P01

Characterizing the Relationship between Petrophysical Trends and Diagenetic Cementation Patterns: A Case Study from a Carbonate Arab Reservoir in the Dukhan Field, State of Qatar

H. Al-Ansi* (Qatar Petroleum), M. Al-Wehaibi (Qatar Petroleum) \& R. Stanley (Qatar Petroleum)

For abstract, PTO

No full paper available 


\title{
15316 Characterizing the relationship between petrophysical trends and diagenetic cementation patterns: A case study from a carbonate Arab Reservoir in the Dukhan Field, State of Qatar
}

\author{
Hussain Al-Ansi (Qatar Petroleum <alansi@qp.com.qa>), \\ Mashael Al-Wehaibi (Qatar Petroleum <m_alwehaibi@qp.com.qa>) and Rowan Stanley (Qatar Petroleum)
}

The Upper Jurassic Arab-C Reservoir in the Dukhan Field is the product of a stable epicontinental shelf subjected to continuous relative sea-level variations, with the preserved sediments representing a complex of syndepositional carbonate lithologies and textures deposited in subtidal, intertidal and sabkha environments. Though the depositional units are spatially correlated within a sequencestratigraphic context, petrophysical observations do not conform to the primary depositional fabric, and a cross-cutting relationship is observed.

Petrographic analysis highlights sporadic occlusion of primary inter-particle porosity by overgrowth burial-diagenetic calcite cements. Though this form of cementation is observed throughout the reservoir, the prevalence is observed to increase significantly below an inferred free-water level (paleoFWL), associated with a concomitant reduction in porosity relative to a preserved higher porosity above the contact. By inference, a continuum of diagenetic overprinting has occurred during burial. It is directly related to the temporal variation in hydrocarbon charge displacing water within the trap, which regulates both the abundance and aqueous-phase transport potential for calcium and carbonate ions. Stylolitic dissolution seams are abundant and may be an important source of calcite dissolution by-products.

The reservoir has a high spatial sampling density of core and petrophysical logs ( $800 \mathrm{~m}$ average well spacing). Detailed analysis of the porosity distribution and trends has facilitated the interpretation of structural closure development during burial, hydrocarbon charge and structural tilting. These processes have interacted to produce the current petrophysical spatial configuration. Doming related to the formation of the Qatar Arch has instigated the recent uplift in the southern part of the Dukhan Field, with the tilt levering diagenetically cemented facies from below the paleo-FWL to a new position above the re-equilibrated current FWL. The paleo-FWL encloses the preserved high porosity interval, and is spatially coincident with a ring of bitumen occurrences. At ground level, the Neogene Hofuf fluvial deposits are uplifted and tilted, and constrain the maximum age for the uplift event.

By virtue of the analysis, process and the recognition of inter-linked structural and diagenetic processes, a unified porosity-trend model has been formulated. It captures the sum of the individual components from a common generic standpoint, and has helped to increase the predictability of the simulated interwell porosity variations. 